\title{
Contemporary Dynamics in Zanzibar's Clove Industry: Prospects and Challenges Facing Smallholder Farmers in Wete District, Pemba, Zanzibar
}

ISSN: 2637-7659

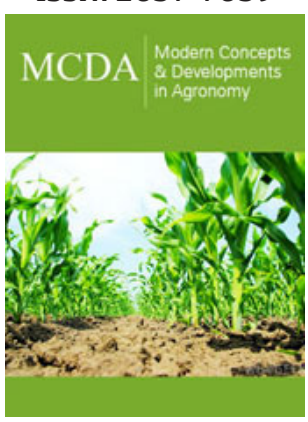

*Corresponding author: Avit Alex Chami, Department of Economic Studies, The Mwalimu Nyerere Memorial Academy-Karume Campus, Zanzibar, P.O Box 307, Zanzibar-Tanzania

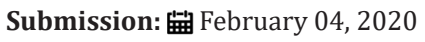

Published: 此 March 02, 2020

Volume 6 - Issue 1

How to cite this article: Avit Alex Chami Contemporary Dynamics in Zanzibar's Clove Industry: Prospects and Challenges Facing Smallholder Farmers in Wete District, Pemba, Zanzibar. Mod Concep Dev Agrono.6(1). MCDA.000627.2020. DOI: 10.31031/MCDA.2020.06.000627

Copyright@ Avit Alex Chami, This article is distributed under the terms of the Creative Commons Attribution 4.0 International License, which permits unrestricted use and redistribution provided that the original author and source are credited.

\section{Avit Alex Chami*}

Department of Economic Studies, The Mwalimu Nyerere Memorial Academy, Tanzania

\begin{abstract}
This study sought to reveal the less known prevailing dynamics in Zanzibar's clove industry in these contemporary times. The study mainly revealed prospects and challenges underlying smallholder clove farming in Kisiwani, Gando and Mtambwe shehias in Wete District, Pemba, Zanzibar. Both desk-based literature survey and descriptive survey research designs were adopted for this study. The study reveals pot holing practices, nursery seedling, dropping system, organic system and shading system as the major clove farming practices available in the study area. Also various dynamics prevailing in the clove industry were revealed including fluctuations in clove production over time, integration of key actors in the clove industry in Zanzibar including actors in clove production and marketing in Zanzibar and the prevalence of dominant monopsony marketing structure in the clove industry in Zanzibar. The study further revealed potential prospects in the clove industry in Zanzibar including putting in-place the following: reliable meteorological services, crop marketing boards, state trading corporation, agricultural innovations interventions, clove smuggling control, government commitment and policy framework interventions in the clove industry. Based on the findings, the study concluded the need of integrating all major key actors in the Zanzibar's cloves industry to work closely in the course of revamping clove productivity among smallholder farmers in the study area. Lastly, the study urges government authorities to undertake deliberate initiatives through policy advocacy to improve smallholder farmers' livelihoods through strengthening capacities in enhancing their resilience on mitigating and adapting the prevailing dynamics in the clove farming in Zanzibar.
\end{abstract}

Keywords: Contemporary dynamics; Clove industry; Prospects; Challenges

\section{Introduction}

Over centuries now, agriculture stands as an important sector in the Zanzibar economy. The sector supports over 70 per cent of the island's population for their livelihood followed by trade and tourism [1]. The production and marketing of cloves have been the economic mainstay of Zanzibar for centuries now. Currently, clove is the major cash and export crop of Zanzibar, hence being a dominant crop in the Zanzibar agriculture sector besides sea weeds, chilies, copra and coconuts [2,3]. Clove is the most important spice of the world next to black pepper. Clove refers to the medium-sized tropical evergreen tree that can live up to more than 100 years with dried unopened flower bud of Syzygium aromaticum belonging to the family myrtaceae $[4,5]$. Clove is one of the most ancient and valuable spices of the orient holding a unique position in the international spice trade [6]. Clove stands as the most important cash crops in Zanzibar since the crop is grown in all five regions where South Pemba region stands as the leading region with planted area of 4,966ha (55.6 percent) and produces 4,276 tons (68 percent) from 4,296ha harvested area [1].

Back to the history from the 1920s onwards, the colonial administration committed to the promotion of "native crops" (in a bid to generate taxes and develop exports for the economy), launched an extensive campaign to encourage small local farmers in the planting of plots of clove trees [7,8]. According to Locatelli, (2000) cited in Juma, [8] this strategy was pursued until recently by projects such as the O.C.P.G.C. (Operation Coffee, Pepper, Clove, Cocoa), which from 1968 and for further 20 years, so was overseeing production. Over years, clove farming has been facing myriad dynamics in terms of its production levels, the way it is conducted, and mostly farming techniques innovated over time [1]. However, Weiss [5] reveals that the dynamics in clove farming were closely associated with time patterns such 
that through increasing production of cloves, modern techniques of farming benefit the farmers socially and economically in several ways, including owning valuable assets, household expenditure on basic needs, incomes from farm and off-farm activities and house ownership. The findings from Small [9] posit modern clove farming techniques playing a significant role in improving the conditions of clove farmers by not only helping the farmers accessing foreign exchange and invest in income generating activities but also enabling individuals to solve fundamental social and economic problems in their households.

Clove farmers in some countries like Philippines and Indonesia have been applying intercropping method as a technique to control weeds in the farms that can destroy clove trees, specifically during early stages [5]. The study done by Zacharia et al. [6] reports that, intercropping and organic manure is sometimes used by farmers to control pests that can lead to harsh conditions to the seedlings and clove trees, including diseases. The results from the same study by Zacharia et al. [6] also show the use of chemicals and tractormounted in harvesting cloves, as well as using of artificial dryers to reduce the damage of clove spoilage during hush weather. Referring to the studies by Zacharia et al. [6] and Small [9], new farming techniques like application of synthetic seeds, molecular breeding, and embryo culture of cloves facilitate both production and economic growth of the farmers which result into poverty alleviation. In relation to economic growth, Weiss [5] describes that application of hybrid seeds and implementation of integrated pest control as a useful strategy in enabling clove farmers to smooth their consumption, better manage their disease risks, gradually build their assets, develop their off farming activities, enhance their income earning. Over $70 \%$ of the smallholder farmers derive their livelihoods from subsistence agriculture by growing cash and food crops and spices including cloves being one of the major cash crops [10]. The prevailing dynamics in the clove industry involve the currently widely adopted new farming methods namely plots of monoculture as a farming technique of clove have all but disappeared and the clove trees are included in more or less complex agro-forestry technique. Adopters of improved technologies increase their productions, leading to constant socio-economic development. Adoption of improved agricultural technologies has been associated with higher earnings and lower poverty; improved nutritional status; lower staple food prices; increased employment opportunities as well as earnings for landless laborers [10,11].

The clove farming in Wete District is taken as supplement to other livelihood activities among local people, which reduces over dependence on natural resources in the area. Since more than $90 \%$ of the clove fields in Wete District are run by men while approximately about $10 \%$ run by women, there has been a need of having more women engaged and get used to various techniques applied from planting, harvesting till processing of cloves. Under myriad dynamics in the clove farming including adopting professional and modern methods of agriculture, urging farmers to own nursery of seedlings, applying dropping system, organic clove farming as well as planting personnel and properly harvesting without cutting branches, clove farming has improved the livelihoods of majority of community members [12]. The prevailing dynamics in the clove industry has recently resulted to the formulation of Zanzibar Clove Development Regulations of 2014 where several standards of operations in the clove farming were instituted. These include prohibiting exposing cloves on roads, veranda, on tin or deliberately contaminating with unneeded materials in cloves. Also, in accordance with regulations cloves, should be dried by using mats or any other clean materials advised by Zanzibar State Trading Corporation. Contrary to all said standards of operations in the regulations was considered as an offence [1].

In the course of shedding light on the contemporary dynamics in the clove farming for many years, it was envisaged that farmers have continued preventing sheet erosion which is common and is very destructive especially in Pemba by practicing intercropping of food crops with tree crops on steep slopes, by terracing, and by mulching and banding. However, under the clove farming system in Pemba, clove trees are cut in order to expand food crops farming, for firewood, charcoal and for building materials hence posing uncertainty to the stability of clove harvests in the study area [10]. On the other hand, the empirical evidence shows that spice farming including cloves have attracted serious concern from the Government. In an effort to raise the yields, the Government of Zanzibar introduced the Government's ten years Clove Development Strategy (CDS) with the major goal of revamping the clove production and regulating clove marketing and trading activities with the supporting of National Development Strategy of MKUZA I. Although there are both successful and unsuccessful cases in spice farming it can be envisaged that enhancing spice farming initiatives has a positive effect on benefits for smallholder farmers and the entire spice industry in Zanzibar [12]. Despite the widely known implemented myriad efforts, initiatives and interventions towards the development of clove industry in Zanzibar including restructuring the clove marketing system, intensifying clove based farming system, introducing high level intercropping, introducing new post-harvest techniques clove farming methods for the improved clove productivity among smallholder farmers [1,10,12$14]$, less remains to be known on the prevailing contemporary dynamics in the Zanzibar's clove industry. This study aimed at revealing the prospects and challenges facing smallholder clove farmers in Wete district, Pemba, Zanzibar. In the course of undertaking this study, the following three specific objectives were answered:

A. To identify the available clove farming practices in the study area.

B. To examine the prospects pertaining clove farming in the study area.

C. To assess the challenges facing clove farming in the study area.

Research Methodology

\section{Study area and research design}

The study was conducted in the three selected shehias namely Kisiwani, Gando and Mtambwe in Wete District, Pemba, Zanzibar. 
The study area is found in Latitude: -5.2167 and Longitude: 39.7333. Following various agricultural practices in the designated study area, the selected area was sought suitable for the study since it is the place where clove farming is highly practiced. Both desk-based literature survey and descriptive survey research design were applied for this study. The multi-stage sampling procedures were adopted for this study [15]. Under this design both quantitative and qualitative approaches were applied to explore a real-life, contemporary bounded cases in the study area over time, through detailed, in-depth data collection methods involving multiple sources of information in relation to the contemporary dynamics in the clove industry in the Zanzibar, mainly revealing the prospects and challenges facing smallholder farmers in the study area. The chosen study design is advantageous as it was compatible to the nature of the study on hand, available time and resources.

\section{Sample size and sampling technique}

The designated sample size of the study was 60 respondents who were treated as the total sample size. In the course of obtaining the reliable scientifically justifiable number of respondents to participate in this study as well as attaining heterogeneity of the views, the sample size determination formula adopted from Bowen [16] was employed to yield the reasonable number of respondents to participate in this present study. The study sample size of 60 respondents was envisaged to yield data and all variables of interest for the study since it was $5 \%$ of the entire available population in the study shehia. These respondents were selected randomly in order to get their diverse views on the subject under study. Study used the sample size comprised of both male and female respondents being picked from two clusters namely Extension Officers and Randomly sampled clove farmers in the selected shehias in Wete District, Pemba Zanzibar. For the purpose of this study, a sampling intensity of $5 \%$ of the total designated group of respondents earmarked for this study was adopted as presented in the Table 1.

Table 1: Somatic diseases and concomitant OMD.

\begin{tabular}{|c|c|}
\hline Designated Groups of Respondents & Randomly Sampled \\
\hline Extension Officers & 10 \\
\hline Randomly sampled clove farmers & 50 \\
\hline Total & 60 \\
\hline
\end{tabular}

\section{Types of data and data collection methods}

In the course of undertaking this study, both qualitative and quantitative approaches were employed for the purpose of having detailed information and ensuring triangulation and complementarily. Both primary and secondary data sources were used as described below.

Primary Data: The study employed primary data where diverse data collection techniques were employed study including questionnaires and interviews. Primary data were collected through self-administered and researcher assisted open and closed questionnaires. The questionnaires were carefully structured to facilitate maximum response from the earmarked respondents. Questionnaires were used to enable the collection of information in a relatively short time without strict supervision of the researcher [16]. The questionnaire method was employed to gather data from all of 60 study respondents and interviews were conducted to all designated respondents from the study area.

Secondary Data: In the course of supplementing the primary data, this study also utilized secondary data in the course of revealing the dynamics of clove farming in the contemporary Zanzibar, mainly revealing the prospects and challenges facing smallholder farmers in Wete district, Pemba, Zanzibar. Secondary data were collected through reviewing previous studies and documented sources like scholarly journals, thesis, books, documents and reports from various sources in relation to the dynamics of clove farming in the contemporary Zanzibar.

Data analysis: The study processed the collected data by the aid of Microsoft Excel and Statistical Package for Social Sciences (SPSS 20.0) computer programs. Both content analysis and descriptive statistical analyses were employed to reveal the magnitudes including percentages of various aspects relating to the dynamics of clove farming in the contemporary Zanzibar, mainly revealing the prospects and challenges facing smallholder farmers in Wete district, Pemba, Zanzibar. Analysis of data used both quantitative and qualitative data analysis approaches including simple percentages, descriptive analysis and explanations to establish relationships of the variables employed in the study.

\section{Result}

After data analysis was performed, the study findings were presented in this section followed by their respective interpretations and discussions in the subsequent section's hereafter.

\section{Socio-economic characteristics of respondents}

Relevant respondents' characteristics were revealed and presented in the following Table 2 below. Following the presented characteristics of respondents in the Table 2 above, the study reveals $75 \%$ of all respondents involved in this study being male respondents, $50 \%$ being aged between $30-49$ years, $40 \%$ had acquired secondary education, $60 \%$ had between $21-30$ years of experience in practicing clove farming in the study area. The fact that this study aimed at revealing the prospects and challenges facing smallholder farmers in Wete district, Pemba, Zanzibar, the earmarked group of respondents in the study area were suitable for revealing relevant information since $40 \%$ had acquired secondary education while $60 \%$ had experience of practicing clove farming in the study area for the long time between 21 and 30 years. These study findings concur Kinyangi, (2014) findings that personal exposure which is accumulated from education level and significant experience in the particular field of an individual hence envisaged to contribute widely to the mastery of the particular intervention in the study area including effective participation in the clove farming. 
Table 2: Characteristics of respondents $(n=60)$.

\begin{tabular}{|c|c|c|}
\hline Characteristics & Frequency & Percent (\%) \\
\hline \multicolumn{3}{|c|}{ Sex of respondents involved in the study } \\
\hline Males & 45 & 75 \\
\hline Females & 15 & 25 \\
\hline \multicolumn{3}{|c|}{ Age of respondents involved in the study } \\
\hline $18-29$ years & 24 & 40 \\
\hline $30-49$ years & 30 & 50 \\
\hline $50-60$ years & 6 & 10 \\
\hline \multicolumn{3}{|c|}{ Education level of respondents involved in the study } \\
\hline Primary education & 11 & 18 \\
\hline Secondary education & 24 & 40 \\
\hline Tertiary education & 25 & 42 \\
\hline \multicolumn{3}{|c|}{ Experience in practicing clove farming in the study area } \\
\hline $1-10$ years & 9 & 15 \\
\hline $11-20$ years & 15 & 25 \\
\hline 21-30 years & 36 & 60 \\
\hline \multicolumn{3}{|c|}{ Positions held by respondents involved in the study } \\
\hline Extension Officers & 10 & 17 \\
\hline Randomly sampled clove farmers & 50 & 83 \\
\hline
\end{tabular}

\section{The available clove farming practices in the study area}

In the course of undertaking this study, it was firstly sought to reveal the available clove farming practices in the study area and major dynamics prevailing along clove farming practices in the study area.

The smallholder farmers clove farming practices in the study area: The study sought to reveal the available clove farming practices which were highly practiced by the smallholder farmers in the study area. The practices presented in the Figure 1 below were revealed by the respondents from the study area as the practices which were widely and frequently applied by the respondents who were also smallholder farmers from the study area. Basing on the study findings, it was revealed that large number of farmers (80\%) adopted organic system of clove farming while shading system of clove farming was practiced by $70 \%$ of all respondents involved in this study, also the study shows pot holing practices were highly practices by majority (90\%) of respondents while dropping system was practiced by $81 \%$ of all respondents as the mainly practiced clove farming method in the study area. On the other hand nursery seedling was reported to be rarely practiced (43\%) such that many respondents mentioned being not widely engaged since the State trading corporation used to supply clove tree seedlings along with other farming inputs.

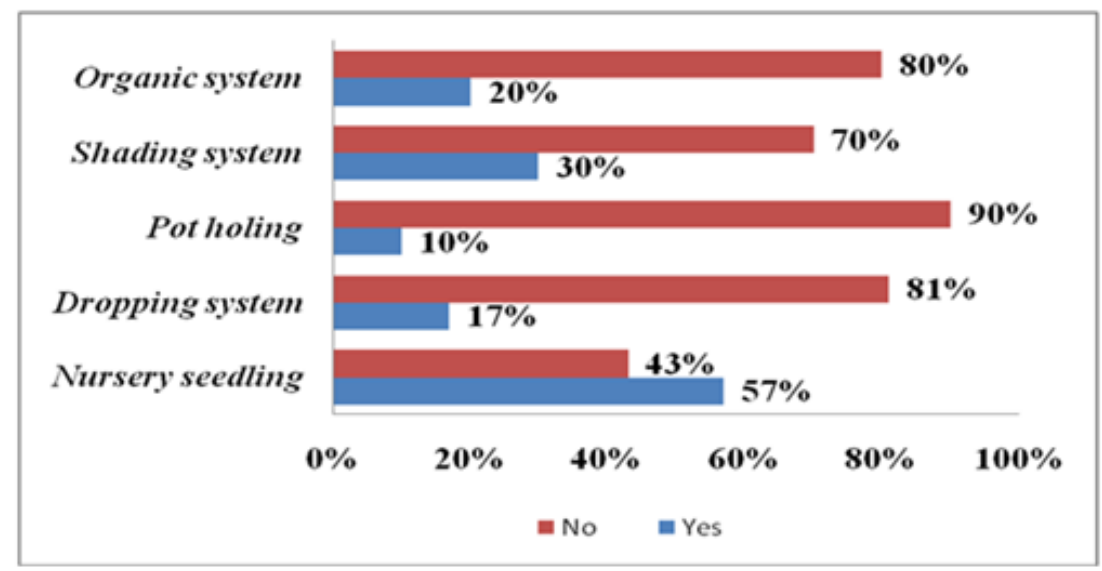

Figure 1: The available smallholder farmers clove farming practices in the study area.

Source: Field Data (2019). 
The dynamics prevailing along clove farming in the study area: The study sought to reveal the dynamics prevailing along the spectrum of clove cultivation in Zanzibar in these contemporary times where a lot of complexities have touched almost every sector from production to the market perspective. The revealed contemporary dynamics in the clove farming were drawn from both the entire clove industry and small-scale farming where the smallholder farmers belong. The dynamics prevailing in the clove faming in Zanzibar include the following: Fluctuations in clove production over time such that despite numerous initiatives being put in place to get rid of all challenges facing clove farming including instituting state trading corporation namely Zanzibar State Trading Corporation (ZSTC) to manage all challenges including crop management and marketing related aspects in the whole clove value chain in Zanzibar, the sector still faces myriad ups and downs movements of the clove harvests. The current situation in cloves industry and especially what was reported by the respondents from three shehias in Wete namely Kisiwani, Gando and Mtambwe. There have been widely reported drop in clove production in recent years which called for measures from Revolutionary Government of Zanzibar. Number of surveys indicates that there has been a significant decline in cloves production and export from the 2000's. Despite the fact that cloves production declined, the sector had large contribution to the economy and provided Zanzibar with the substantial income per year and significantly contributed to the country's GDP. In 1834 Zanzibar produced 35,000 tons of cloves that represented $90 \%$ of the world clove market at the time [17]. The production volume of about 16,000 metric tons of cloves peaked in Zanzibar in the 1970's and reached a significance level. However, it was reported that the volumes of cloves production declined by about 65 percent in the last ten years, due to a cyclical nature of the crop itself [11].

Integration of key actors in the cloves industry in Zanzibar is envisaged to result to harmonized coordination of many actors involved in clove production and marketing in Zanzibar including clove farmers, clove pickers and private cloves rentals, the Ministry of Trade, Industry and Marketing, Ministry of Agriculture and Zanzibar State Trading Corporation [17]. Each actor has significant role in contributing to the success of the clove industry in Zanzibar. The fact that the earmarked actors are under the supervision of government's laws and regulations, their roles are summarized in the Table 3.

Table 3: Key actors in the cloves industry in Zanzibar.

\begin{tabular}{|c|c|c|}
\hline S. No & Actor & Roles \\
\hline 1 & Clove Farmers & $\begin{array}{l}\text { Farm preparation, clove planting, caring, harvesting, drying, } \\
\text { cleaning, handling and transporting to the selling point. }\end{array}$ \\
\hline 2 & Clove Pickers & Harvesting and separating between cloves and cloves stem. \\
\hline \multirow{3}{*}{3} & \multirow{3}{*}{$\begin{array}{c}\text { Ministry of Trade, Industry and } \\
\text { Marketing }\end{array}$} & $\begin{array}{l}\text { Ensure the State Corporation fulfills their tasks efficiently and } \\
\text { effectively. }\end{array}$ \\
\hline & & $\begin{array}{l}\text { Ensure farmers have better conditions and access to services such } \\
\text { as extension, loans, subsidized inputs and better prices. }\end{array}$ \\
\hline & & $\begin{array}{l}\text { Responsibility for the growth of cloves industry and encouraging } \\
\text { farmers to investing in this sector. }\end{array}$ \\
\hline \multirow{2}{*}{4} & \multirow{2}{*}{$\begin{array}{l}\text { Ministry of Agriculture and } \\
\text { Natural Resources }\end{array}$} & Extension services to clove growers and other cloves stakeholders; \\
\hline & & Agricultural research on clove. \\
\hline \multirow{5}{*}{5} & \multirow{5}{*}{$\begin{array}{l}\text { Zanzibar State Trading } \\
\text { Corporation }\end{array}$} & $\begin{array}{c}\text { Providing inputs services, including implements, equipment, } \\
\text { fertilizers and chemicals, post-harvest management and handling } \\
\text { materials; }\end{array}$ \\
\hline & & $\begin{array}{l}\text { Promoting production, marketing, processing, storage and trade of } \\
\text { cloves and other agricultural products; }\end{array}$ \\
\hline & & $\begin{array}{l}\text { Collection, analysis, marketing, processing, storage and trade of } \\
\text { cloves and other agricultural products; }\end{array}$ \\
\hline & & $\begin{array}{l}\text { Promoting technological advancement in cloves and other } \\
\text { agricultural products activities; }\end{array}$ \\
\hline & & $\begin{array}{l}\text { Providing assistance in the formation and support of farmers and } \\
\text { actors, farmers group, co-operatives organizations. }\end{array}$ \\
\hline
\end{tabular}

Following the presented roles of the key actors in the cloves industry in Zanzibar, this study envisages the most efficient and effective outcomes from the well synergized, coordinated, shared and harmonized roles of each among many actors involved in clove production and marketing among smallholder clove farmers. The fact that clove farmers are classified in small scale sizes whereby there are farmers who own between one to ten acres, ten to twenty acres, and above that being surrounded by numerous bottlenecks, the role of all actors should focus at improving the smallholders farmers' income through acquisition of better prices and maintaining the quality of Zanzibar cloves. This among others, call for the integration of various potential actors to ensure farmers to acquire better conditions and access to services such as extension, loans, subsidized inputs and better prices. The basic role in ensuring the growth of cloves industry include ensuring farmers to be able to manage to access inputs such as fertilizer, seedlings, 
extension services and technology that can help farmers to be effective in production.

Prevalence of dominant monopsony marketing structure in the clove industry where the Zanzibar State Trading Corporation is responsible for sustaining both production and export of cloves in Zanzibar, the functions and what the ZSTC are supposed to provide for cloves farmers in sustaining the cloves production, reducing farmers' constraints and encourage in investing in this sector. This study explores on how the monopsony system could be responsible for implications in investing, production and sale of cloves; while numerous efforts and strategies were put in places to make sure that farmers managed to produce high yields and maintained quality in the entire cloves sector in Zanzibar. Less competition in the market always results to inefficiency of the systems involved in the price determination process. Continuation of state monopsony marketing system in cloves sector in Zanzibar seems to limit farmers' participation which has been brought about direct implication for cloves producers. Closed marketing system to some extent worsens the producers' decision and reinforces them to channel their resources to other favorable economic sectors. Besides various kinds of treatments availed to farmers by ZSTC including providing farmers with low priced inputs such as the special mats for clove drying during the harvest seasons, free seedlings and free transport from household to the buying center for those farmers who have more than $100 \mathrm{~kg}$ of cloves, yet the smallholder farmers rewarding system must be attached to the competitive models in the clove world market. This could have been a useful promotional strategy for strengthening the cloves sector in Zanzibar [1]. Though there are various dynamics facing clove industry in Wete, Pemba; the existence of unreported facts on cloves trees population and area harvested decrease in last ten years resulting from either farmer preferring to chop down the clove tree for making charcoal or use as timber or substitution with other food crops. On the other hand, it was revealed that most of clove trees are aging with massive decline in clove production and investment. These dynamics poses the industry in a position to continue facing various problems in the areas of production, marketing, processing and smuggling in and out of Zanzibar [17].

\section{The prospects pertaining clove farming in the study area}

Based on the study findings prospects pertaining clove farming in the study area and the fact that the economy of Zanzibar depends significantly on rain fed agriculture, which is highly vulnerable to the amount and distribution of rainfall. Both spatial rainfall anomalies over the region and temporal variability within the wet season itself can be prominent and lead to significantly deficiencies. The clove market characteristics among others include revealing potential prospects include planning for suitable measures for mitigating the problems in the clove industry meteorological services, crop marketing boards, state trading corporation, state marketing boards, agricultural innovations, clove smuggling control, government commitment and policy framework interventions which also reflects views and knowledge from Abuubakar [2].

The revealed prospects in the clove industry are very encouraging since there have been prevalence in various agricultural innovations, diffusion and dissemination of new farming techniques are fundamental aspects in the efforts of developing countries to enhance food security and agricultural modernization in particular [6]. It is pertinent to note that more ongoing research and study is essential in order to understand clearly why improved agricultural technologies are not being effectively adopted, in order to address major problems in the clove industry (Figure 2). This is especially the case of clove farmers who are in most instances reluctant to adopt new farming techniques and agriculture innovations as well as recent intensification of meteorological services, crop marketing boards, state trading corporation, state marketing boards, agricultural innovations, clove smuggling control, government commitment and policy framework interventions, hence reflecting findings in the ZSTC [1].

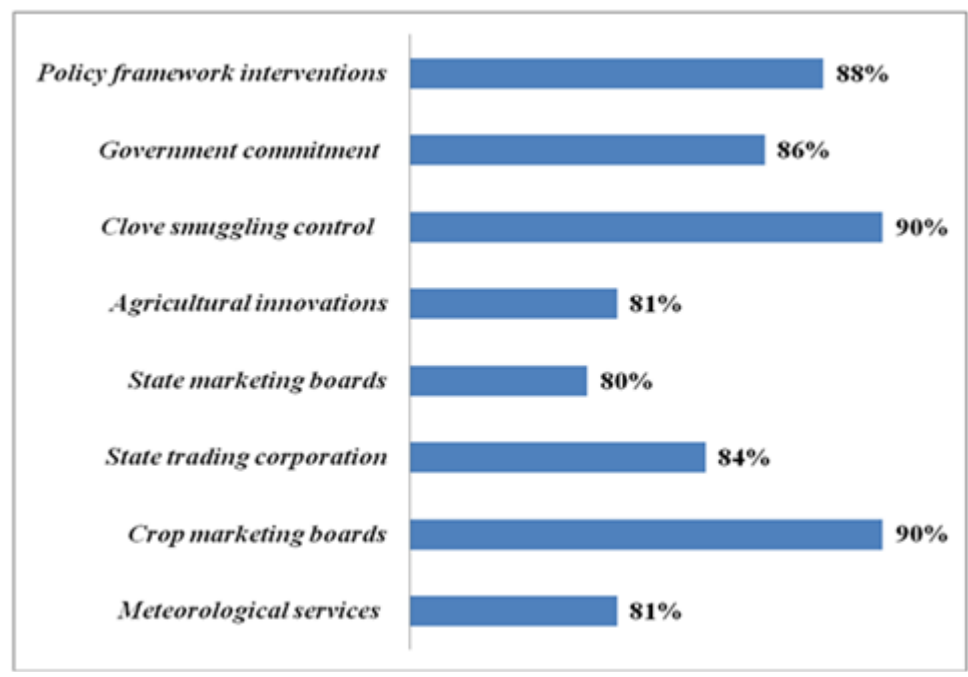

Figure 2: The available smallholder farmers clove farming practices in the study area.

Source: Field Data (2019). 
The existing prospects in the clove sector ensure sustainability of the industry as it is widely supported by the government. The fact that clove is not only a crucial cash crop grown primarily for export in the Zanzibar economy and the main source of foreign exchange, the revealed prospects have managed to control the factors distressing the clove industry makes the clove sector become a source of cash income for the majority of households in Zanzibar.

\section{The challenges facing clove farming in the study area}

The study went further to reveal challenges facing clove farming in the study area. The study findings presented in the Table 4 revealed challenges facing clove farming in the study area being classified into four groups namely environmental, social, institutional and economic challenges which were reported by study respondents in the study area. From the study findings, environmental challenges including nature of the land, size of the farm, inconsistent clove production, unpredicted climate changes and weather-related clove distress where respondents from three shehias in Wete namely Kisiwani, Gando and Mtambwe reported the said challenges in various levels. The study findings are in line with the findings from studies conducted in Sub-Saharan Africa by Mwino et al. [18] and Miraji [13] such that major challenges include economic challenges which have been widely posited as market forces which contains the following: availability of labor, clove farming resource requirements, farm size, level of expected benefits, and level of effort required to implement the clove farming. However, majority of literatures further posit economic challenges including assets, income, institutions, vulnerability, awareness, labor and innovativeness by smallholder farmers [19,20].

Table 4: The challenges facing clove farming in the study area.

\begin{tabular}{|c|c|c|c|c|}
\hline & \multirow{2}{*}{ Challenges } & \multirow[b]{2}{*}{ Kisiwani \% } & \multirow{2}{*}{$\begin{array}{c}\text { Shehia } \\
\text { Gando \% }\end{array}$} & \multirow[b]{2}{*}{ Mtambwe \% } \\
\hline & & & & \\
\hline \multirow{5}{*}{ Environmental challenges } & Nature of the land & 3 & 11 & 15 \\
\hline & Size of the farm & 9 & 15 & 20 \\
\hline & Inconsistent clove production & 18 & 41 & 20 \\
\hline & Unpredicted climate changes & 41 & 30 & 20 \\
\hline & Weather related clove distress & 29 & 3.7 & 25 \\
\hline \multirow{5}{*}{ Social challenges } & Negative attitude among farmers & 3 & 7 & 24 \\
\hline & Peer pressure among farmers & 9 & 10 & 5 \\
\hline & Lack of awareness among farmers & 48 & 48 & 24 \\
\hline & Lack of best practices & 24 & 19 & 12 \\
\hline & Low level of education among farmers & 18 & 26 & 34 \\
\hline \multirow{4}{*}{ Institutional challenges } & Policy framework & 61 & 59 & 78 \\
\hline & Lack of bottom-up strategies & 9 & 15 & 2 \\
\hline & Poor motivation schemes & 18 & 22 & 15 \\
\hline & Inadequate capacity building programs & 12 & 4 & 5 \\
\hline \multirow{5}{*}{ Economic challenges } & Inadequate financial resources & 28 & 20 & 17 \\
\hline & High clove production cost & 60 & 52 & 40 \\
\hline & Poor clove handling infrastructures & 2 & 7 & 16 \\
\hline & Clove farming input price instability & 40 & 8 & 17 \\
\hline & Clove price instability & 6 & 13 & 10 \\
\hline
\end{tabular}

On the other hand, social challenges are widely posited as: age and experience of potential clove farmers, social status of farmers, education level and gender-related aspects, household size, and farming experience. Also on the side of institutional and management challenges there were revealed as follows; structure and membership to organizations, the capacity to borrow and concerns about environmental degradation and human health of clove farmers; institutional/technology delivery mechanisms: information access, extension services and prior participation in and training in pest control practices. On the other group of authors, the challenges are classified into human capital, production, policy and natural resource characteristics in the similar study areas $[10,13]$. While others place challenges into three groups namely informational, economic and ecological; most farmers were worried of low yield, low education, old age farmers who did not believe new technology and only believe their own experience, old behavior of cultivation practices embedded in farmers for long period: were not persuaded to use new technology.

The study findings further reflect findings in several countries that there is a wide application of synthetic seeds as a new best 
way to boost clove production, which in turns increase earnings to the farmers. In other areas, farmers have been reported using molecular breeding as a technique of increasing yields in clove production, and to some extent the method has shown successful production in the areas where they had practiced [9]. To some extent these difficulties are hindering the development of the sector in general and at the same time failing to perform well in the world market. Relatively, climate variations, insecurity of the three-acres land tenure system, diseases, poor management, limited replacement, ageing of clove trees and monopoly of clove marketing systems that put off private sector investment could be strong reasons for the declined of cloves production and export [8]. Before the 2000's both cloves production and export volume were higher with the average of about 16,000 tones while from 2000's onwards the average production decline compatible with the area harvested. The reasons might be the attitudes of some clove farmers chopping down the clove trees and use as raw materials for making charcoal which partly get sold and some kept for domestic purposes; inefficiency of the provision of quality services by state marketing board which completely control the cloves market in Zanzibar; slow replanting of new cloves; and the natural life cycle of clove trees that take 10 years to be ready for harvesting.

\section{Conclusion}

The study concludes pot holing practices, nursery seedling, dropping system, organic system, shading system as the highly practiced clove farming practices in the study area. Based on the study findings the study concluded major prospects including the existence of reliable meteorological services, crop marketing boards, state trading corporation, state marketing boards, agricultural innovations, clove smuggling control, government commitment and policy framework interventions. On the other hand the study concluded the modern dynamics facing clove industry in Zanzibar including clove quantity fluctuations over time, prevalence of dominant monopsony marketing structure and lack of well synergized, coordinated, shared and harmonized roles of each among many actors involved in clove production and marketing among smallholder clove farmers. Finally the study concluded major challenges facing clove farming including environmental challenges, social challenges, institutional challenges and economic challenges in the three shehias in Wete namely Kisiwani, Gando and Mtambwe.

\section{Recommendations}

In the course of sustainably improving the clove industry in Zanzibar; the following recommendations were put forward to following actors:

A. Smallholder farmers are urged to embrace all capacity building interventions to be able to revive the clove industry including the adoption of new farming techniques in Wete, Pemba. Farmers should be responsible in improving their own individual farming skills to cope with the prevailing modern dynamics in the clove industry.
B. Ministry of Agriculture and Natural Resources and Ministry of Trade, Industry and Marketing as potential government actors in the clove industry; are widely urged to enhance their extension services and other related roles to clove farmers in the study area and the entire Zanzibar at large. However, there should be deliberate initiatives through policy advocacy to improve smallholder farmers' livelihoods including strengthening capacities and enhancing resilience on mitigating and adapting the prevailing dynamics in the clove farming in Zanzibar.

C. Zanzibar State Trading Corporation is urged to enhance their market operations such that smallholder farmers should finally get competitive prices for their produce. The existing clove marketing system in Zanzibar namely monopsony seems to be inefficient in offering competitive prices to smallholder farmers; such that it is now widely urged to be high time to review the marketing system to make it more flexible to completely manage and eradicate smuggling problems in the entire clove industry in Zanzibar.

\section{References}

1. ZSTC (2015) Zanzibar state trading corporation. Fact sheet, Zanzibar, Tanzania.

2. Abuubakar A (2013) Zanzibar Clove Growers Organization (ZACPO), Rescuing the clove industry by implementing Zanzibar's clove development strategy. Fact Sheet.

3. Revolutionary Government of Zanzibar (2003) A study of the clove industry in Zanzibar, Tanzania.

4. Bulbeck D, Reid A, Tan LC, Wu Y (1998) South East Asian exports since the $14^{\text {th }}$ Century Cloves, Pepper, Coffee, and Sugar. Institute of Southeast Asia, Singapore.

5. Weiss EA (2002) Spice Crops. CAB Publishing, UK.

6. Zacharia TJ, Parthasarathy VA, Chempakam B (2008) Chemistry of spices. CAB Internatioal, UK.

7. Blakeney M, Mengistie G (2011) Zanzibar: Cloves extending the protection of geographical indications: Case studies of agricultural products in Africa 15: 330.

8. Juma J (2010) Zanzibar Clove Growers Organization (ZACPO) Final Clove Advocacy Report. pp. 1-18.

9. Small E (2012) Top 100 exotic food plants. CRC Press, Florida, USA.

10. Hamad MB (2019) Factors affecting adoption of new clove farming techniques among smallholder farmers of in Zanzibar. A case of selected villages in Wete District Pemba. A research dissertation submitted in partial fulfillment of the requirements of the bachelor's degree in economics of development from the Mwalimu Nyerere Memorial Academy-Zanzibar Campus, Tanzania.

11. Bank of Tanzania (2013) Monthly Economic Review.

12. Revolutionary Government of Zanzibar (2010) Ministry of Finance and Economic Affairs: Zanzibar Country Analysis-Final Report Economic Research Bureau University of Dar es Salaam, Tanzania.

13. Miraji KM (2013) The effect of weather on clove production in Pemba Island Tanzania: Project work submitted in partial fulfilment of the requirement for post-graduate diploma in meteorology. Department of Meteorology, University of Nairobi, Kenya. 
14. Revolutionary Government of Zanzibar (2009) Socio-Economic Survey 2009. Preliminary report, The office of the chief government statistics, Zanzibar, Tanzania.

15. Babbie E (1992) The practice of social research, California, USA.

16. Bowen GA (2009) Document analysis as a qualitative research method. Qualitative Research Journal 9(2): 27-40.

17. Revolutionary Government of Zanzibar (2004) The Zanzibar clove development strategy and review of functions of ZSTC final report: Economic Research Bureau University of Dar es Salaam, Tanzania.
18. Mwino L, Tan LC (2012) Clove marketing policy in Zanzibar: Does it benefit cloves producers? A policy paper presented to policy analysis course in Zanzibar, Tanzania.

19. Ministry of Agriculture Livestock and Environment (2010) Irrigation infrastructure development report. Government Press, Zanzibar, Tanzania.

20. Martin PJ (1989) Zanzibar Clove cultivation manual. Zanzibar Clove Research Project, Ministry of Agriculture, Livestock and Natural Resource \& United Kingdom's Overseas Development Administration (ODA).

For possible submissions Click below: 